\title{
Emotions, Happiness and Growth: Spinoza, James, and Ramsey
}

\author{
João Ricardo Faria ${ }^{1}$
}

\begin{abstract}
This paper adapts the Ethics of Spinoza into the Ramsey growth model and shows that the way people conceive and understand life, related to emotions of joy and sorrow, affects economic performance. The model has multiple equilibria: The Spinoza solution - optimism - leads to greater capital accumulation, income and consumption levels, while William James's solution - pessimism leads to a worse economic performance. The Ramsey model, where emotions balance, lies in between these two solutions, showing that the neoclassical growth model can be seen as a particular case of the Spinoza model. Finally, regarding the relationship between emotions and economics, in the Spinoza and William James solutions emotions and happiness are determined independently from economic variables. Only in the Ramsey case are emotions explained by income and consumption.
\end{abstract}

'Are you so unobservant as not to have found out that sanity and happiness are an impossible combination? No sane man can be happy, for to him life is real and he sees what a fearful thing it is. Only the mad man can be happy and not many of those.' The Mysterious Stranger, Mark Twain (1916).

\section{INTRODUCTION}

$\mathrm{D}$

OES THE WAY WE CONCEIVE AND UNDERSTAND OUR LIVES MATTER for our eCOnomic decisions? Do emotions affect our economic behaviour? Can feelings of joy and sorrow affect economic growth, our income, our consumption pattern or how much to save and accumulate in capital? Or, conversely, is it possible to explain human happiness and emotions as being determined by income or consumption levels?

Some of these questions have been tackled by the large literature on happiness. The economic literature on happiness seeks to identify the determinants of happiness based on economic, social, institutional and environ- 
mental conditions (e.g. Clark et al., 2001; Namazie and Sanfey, 2001). This literature covers a wide list of subjects, ranging from wage differentials and discrimination, to marriage (for overviews see Oswald, 1997; Frey and Stutzer, 2002). According to Frey and Stutzer (2005), causality is an important issue in this literature since happiness, instead of being an endogenous variable, can be the explanatory variable. Therefore, we may have an open empirical question of causality or reverse causality between happiness and economics.

Although related to the broader question of the meaning of life and its relationship with economics, this article is not directly linked to the literature on happiness. However some of our results may have direct implication for the research on happiness. In this paper the emotions of Joy and Sorrow are not related to the 'happiness' and its proxies as economists usually think of it. They have to do with a weltanschauung, a 'world conception' or 'world view' of a given person. One's conception of life is based on an insightful understanding of the human condition that transcends material well-being and welfare. The paper addresses the questions above by examining a model based on a particular world view as exposed in Spinoza's Ethics (1677). In Spinoza's view the key to happiness is the rational understanding of emotions (Ethics IV, Appendix IV).

Our main objective is to adapt Spinoza's Ethics into an economic framework, in order to study its insights and possible consequences for economics. ${ }^{2}$ We also use some ideas of William James's The Varieties of Religious Experience (1902) on human nature, to better characterise optimism and pessimism. This is a new approach to James's contributions to economics, and it is in line with Barbalet's (2008) findings that the key element in James's psychology is his appreciation of emotions. William James's work has recently gained attention in economics, in particular in institutional economics (Twomey, 1998; Hodgson, 2003). For instance, Lawlor (2006) stresses that James's pragmatism offers an evolutionary philosophy of knowledge; and a foundation of a theory of human nature. James's treatment of habits is crucial in this literature, and it is considered fundamental for Veblen's views.

The neoclassical growth model, also known as the Ramsey model, given its simplicity and malleability, is the chosen framework for our exercise. The use of this framework has an interesting consequence, since it sheds lights on the role of emotions on economic growth and macroeconomic variables such as income, consumption and capital stock.

We obtain three neat results regarding the relationship between emotions and economics. First, the way we conceive and understand our lives, being optimistic or pessimist, affect our economic behaviour, making a difference in terms of capital accumulation, consumption and income. Second, we show that the Ramsey model can be seen as a particular case of Spinoza's model, in which joy and sorrow balance. Last but not least, we derive closedform solutions for the determination of emotions, assessing whether happiness determines or is determined by economic variables. 
This paper is structured as follows. The next section discusses Spinoza's Ethics and William James's insights on human nature in order to adapt them into the Ramsey model. Section three presents Spinoza's model. Section four analyses three particular solutions of the model. Finally, section five concludes.

\section{SPINOZA's ETHICS AND WiLliam James'S IDEAS}

Death and suffering trigger emotions that may cause the pursuit of joy to appear foolish and unrealistic. These emotions can make one's life miserable, as Satan presents it clearly in the opening quote from Mark Twain. However, according to Spinoza's Ethics (1677) the rational understanding of our emotions can guard us from being affected by evil emotions. The use of reason helps us to discover the causes of negative emotions and their mechanics. Reason helps controlling emotions, since as soon as we form a clear idea of an emotion it ceases to be a passion (Ethics, V, Prop.III). ${ }^{3}$ Even when we do not possess a perfect knowledge of our emotions, in which case we cannot control our emotions completely as the Stoics and Descartes thought, reason helps us to frame a system of right conduct, or fixed practical precepts, to apply it to the particular circumstances of life (Ethics, V, Prop. X). Spinoza's solution is simple: whenever confronted by negative stimuli the individual should substitute emotionally competent stimuli capable of triggering positive, nourishing emotions (Damasio, 2003, p. 275). For instance, hatred should be overcome with love; fear should be overcome by courage. As reason helps us to understand, to control and to transform emotions, it results in freedom, because we become less dependent on the object-emotional needs that enslave us. In addition, we become more knowledgeable about human condition that gives us joy (Ethics, V, Props. XXXII and XXXVI). This intellectual feeling is Spinoza's amor intellectualis Dei. It is worth noticing that in his classical Principia Ethica, Moore (1903, Chap. IV) criticizes Spinoza's 'intellectual love' of God as a naturalistic fallacy.

The rational understanding of the meaning of our life leads us to resist or dominate suffering. In Spinoza's words: 'the pain arising from the loss of any good is mitigated, as soon as the man who has lost it perceives, that it could not by any means have been preserved' (Ethics, V, Prop. VI, Note).

What is the economic behaviour of an individual that acts according to Spinoza's Ethics? In order to answer this question, it is important to notice that Spinoza's philosophy implies the reconsideration of an individual's emotions, preferences and production decisions.

First, the individual requires something more out of life beyond the pursuit of pleasure and the accumulation of possessions. Spinoza's representative agent, what he calls the wise man, is an individual who seeks joy and minimises sorrow by achieving some clarity about the meaning of his own life. In economic terms we can think of a constraint in which a rational individual is 
able to understand, compare, control and transform emotions. In Spinoza's solution, the individual transforms negative into positive emotions aiming at achieving a state in which joy is greater than sorrow.

Second, the role of emotions is also reflected in an extended utility function that includes feelings such as joy and sorrow, since they capture something different from the ordinary utility of consumption of goods.

Third, according to Spinoza, the pursuit of honour, rank and wealth should be done rationally by considering its right use, the end for which it should be pursued, and the means whereby the individual attain it (Ethics V, Prop. X, Note). In economics, this means that economic decisions ought to be made based on considerations of efficiency, distribution and externalities. Important here is the idea of a self-interested individual finding the best way to produce something and enjoying himself doing it - what Spinoza calls selfapproval, the pleasure arising from a man's contemplation of himself and his own power of action (Ethics IV, Prop. LII). This ethical behaviour has a clear implication concerning production decisions given by a production function that reflects the pursuit of joy and the minimisation of sorrow. ${ }^{4}$ Another possible implication of Spinoza's ethical behaviour concerning production decisions is that it may lead to greater cooperation (Ethics IV, Appendix XII, XIV). ${ }^{5}$

At this point it is useful to use the terminology of William James's (1902) The Varieties of Religious Experience, to characterise optimism, pessimism and neutral states. According to James, Spinoza's view is that of an optimist, which he calls the healthy-minded temperament, are individuals who seek joy and minimise sorrow. James characterises the pessimists as sick souls; they cannot contemplate nature and enjoy the spectacle; for them sorrow is greater than joy. Finally, we postulate a neutral state in which these emotions balance. In this paper we show that when emotions balance, this corresponds to the Ramsey model.

James (1902), in contrast to Spinoza, believes that more sorrow and less joy is key for the understanding of life's significance: 'there is no doubt that healthy-mindedness is inadequate as a philosophical doctrine, because the evil facts which it refuses positively to account for are a genuine portion of reality; and they may after all be the best key to life's significance, and possibly the only openers of our eyes to the deepest levels of truth' (James, 2004, p.148).

The introduction of the extended utility and production functions and the constraint related to the transformation of emotions in the Ramsey model, allow us to analyse the relationship between emotions and economics. This paper focuses on three distinct scenarios - optimism, pessimism and neutral - that emerge by considering whether or not there is a balance between joy and sorrow. It shows that optimism leads to greater accumulation of capital, higher income and consumption, whereas pessimism leads to the worst economic scenario with lower capital stock, income and consumption. Incidentally, the Ramsey model lies in between these two scenarios, showing that the neoclas- 
sical growth model can be seen as a particular case in which emotions play little role in economics because they are assumed to balance.

\section{SPINOZA'S MODEL}

As discussed above, the most salient characteristic of the Spinoza model is the existence of a constraint related to the transformation of emotions. In Spinoza's Ethics, reason leads to the understanding and control of negative emotions and the generation of positive ones: it leads to the transformation of sorrow into joy, i.e., Spinoza's representative agent seeks joy by minimising sorrow. For William James it is the other way around, the individual seeks sorrow by minimising joy. Assume a general function $H$ that has as arguments joy $(J)$ and sorrow $(S) ; H(J, S)$

In Spinoza's case the problem is:

$$
\underset{S}{\operatorname{Min}} H(J, S) \Rightarrow J=T(S)
$$

In James's case the problem is:

$$
\operatorname{Min}_{J} H(J, S) \Rightarrow S=Q(J)
$$

Spinoza's extended utility function, $V$, can be thought as having joy $(J)$ and sorrow $(S)$ as arguments, besides the consumption good $(c): V(c, J, S)$, $V_{c}>0 ; V_{c c}<0$. It must be stressed that feelings of joy or sorrow differ from the effects of consumption of a good or a bad. They result from the understanding or lack of understanding of human emotions related to one's ordinary life. The properties of this extended utility function vary according to the thinker: for Spinoza sorrow is bad and joy is good $\left[V_{S}<0 ; V_{J}>0\right]$, and for William James, sorrow is good and joy is bad $\left[V_{S}>0 ; V_{J}<0\right]$.

Regarding production decisions, Spinoza's representative agent takes into account in her production function not only capital $(k)$, but also emotions, joy and sorrow. As discussed above, negative emotions such as envy, result in bad production decisions, ${ }^{6}$ while positive emotions may lead to better production decisions. For instance, the sense and pursuit of accomplishment, in which the individual is always excelling himself, the sense of duty may lead to greater efficiency and cooperation.

Of course the simple introduction of emotions as inputs in a production function is rather controversial. However, one can think of a production function $\mathrm{f}$ with capital $k$ and managerial skills $M$ as arguments, $f(k, M), f_{k}>0 ; f_{k k}<0 ; f_{M}>0 ; f_{M M k}<0$. Good managerial skills create a work environment conducive to higher productivity. Managerial skills are used to minimise coordination and monitoring costs. In our context, they minimise negative emotions such as rumours and envy, which lead to less competition among team members; and maximise positive emotions, increasing cooperation among team members. Thus $M(J, S), M_{J}>0 ; M_{S}>0$. In this sense, 
by controlling emotions in the work environment, managerial skills lead to greater productivity. Therefore we postulate a production function:

$$
f(k, M(J, S))=F(k, J, S), \quad F_{k}>0 ; \quad F_{k k}<0 ; \quad F_{J}>0 ; \quad F_{S}<0
$$

Note that in the production function there are no ambiguities as in the utility function, since James's (1902) defence of pessimism appears to have no implications concerning production decisions.

Inserting the constraint on emotions and the extended utility and production functions into the Ramsey model yields Spinoza's model:

$$
\underset{c, J, S}{\operatorname{Max}} \int V(c, J, S) e^{-\theta t} d t
$$

subject to: $\dot{k}=F(k, J, S)-n k-c$

$J=T(S)$ or $S=Q(J)$

In this setup, feelings of joy and sorrow are control variables that may affect economic decisions regarding consumption, savings and income. It is important to notice that this model has multiple equilibria. We can only find closed form solutions if we make explicit all the functions involved. In this regard, we focus on simple solutions associated with optimism, pessimism and neutral states according to Spinoza and James's cases.

In order to generate crisp results we assume the following functions:

$$
\begin{gathered}
H(J, S)=\frac{1}{2}(J-S)^{2}+e(J+S) \\
V(c, J, S)=c^{\alpha}+J^{\beta}+S^{\delta} \\
F(k, J, S)=g(J, S) f(k)=(1+a(J-S)) f(k)
\end{gathered}
$$

From equation (1) the constraint on emotions becomes very simple. In the Spinoza case optimism, minimising (1) on $S$, yields the following transformation function: $J=T(S) \Rightarrow J=S+e$, where $e$ is a positive constant. In the William James case pessimism, minimising (1) on $J$, yields the following transformation function: $S=Q(J) \Rightarrow S=J+e$.

For simplicity the utility function in equation (2) is separable in its arguments and has the following characteristics. In Spinoza's case: $\alpha$ and $\beta$ are in the unitary interval $(0,1)$, and $\delta<0$. In William James's case: $\alpha$ and $\delta$ are in the unitary interval $(0,1)$, and $\beta<0$. The production function in equation (3) describes linear efficiency gains from positive emotions, where $\alpha$ is a positive constant. Although debatable whether such a straightforward effect exists 
this assumption, as other assumptions above for equations (1) and (2), aim at simplifying our analysis; we do not claim they are actual descriptions of emotions, preferences and technology.

\section{OPTIMISTS, PESSIMISTS AND RAMSEY}

In this section we examine three particular solutions of interest that characterise the states of optimism, pessimism and neutrality. In the first solution there is a balance between joy and sorrow, which defines the neutral state. The second solution is Spinoza's own solution, optimism, where joy is greater than sorrow. The third solution is the pessimist scenario, called the William James solution, where sorrow is greater than joy.

\subsection{Balance of emotions: Ramsey solution}

In the first solution there is a balance between joy and sorrow so that a priori we have: $J=S$. In this case there is no constraint on emotions, and the constant $e$ is identically equal to zero: $e=0$. In addition, notice that in the particular case where the efficiency parameter of emotions in the production function $a$ is equal to one, $a=1$, it follows that $F(k, J, S)=f(k)$. Solving the model in this case gives us the following steady state solutions:

$$
\begin{aligned}
& f_{k}=\theta+n \\
& c=f(k)-n k
\end{aligned}
$$

These solutions correspond to the well-known Ramsey model, where equation (4) is the modified golden rule that determines the equilibrium amount of capital $\left(k^{*}\right)$ and equation (5) determines equilibrium consumption $\left(c^{*}\right)$. In order to obtain explicit solutions, let us assume a well-behaved production function $f(k)=k^{\xi}, \xi \in(0,1)$. Therefore the equilibrium stock of capital in the Ramsey model is:

$$
k^{*}=\left(\frac{n+\theta}{\xi}\right)^{1 /(\xi-1)}
$$

It must be stressed here that the Ramsey model can be seen as a particular case of Spinoza's model, where there is a balance between emotions. Moreover, notice that in this solution, emotions - sorrow $(S)$ and joy $(J)$ - are determined [or caused] by income, $\mathrm{f}\left(k^{*}\right)$, and consumption, $c^{*}$ :

$$
J^{*}=S^{*}=\left(\frac{\alpha\left(c^{*}\right)^{\alpha-1}}{\delta} b f\left(k^{*}\right)\right)^{\frac{1}{\delta-1}}
$$




\subsection{Optimism: Spinoza solution}

Regarding the Spinoza solution optimism, in which sorrow is transformed into joy: $J=S+e$, we can rewrite this equation as: $S=j-e$ to eliminate sorrow from the Spinoza model. In order to find Spinoza's solution let us consider the corresponding Hamiltonian function:

$$
\mathrm{H}=c^{\alpha}+J^{\beta}+(J-e)^{\delta}+\lambda\left[(1+a e) \quad k^{\xi}-n k-c\right]
$$

where $\lambda$ is the co-state variable for the dynamic budget constraint. In the steady state:

$$
\dot{k}=\dot{\lambda}=0
$$

the optimality conditions are:

$$
\begin{gathered}
\beta J^{\beta-1}+\delta \quad(J-e)^{\delta-1}=0 \\
(1+a e) \xi k^{\xi-1}=n+\theta \\
(1+a e) \quad k^{\xi}=n k+c \\
\alpha \quad c^{\alpha-1}=\lambda
\end{gathered}
$$

The most appealing characteristic of the Spinoza solution is that emotions [joy and sorrow] are determined independently from economic variables, such as consumption or income. In order to see this note that equation (7) determines joy $\left(J^{*}\right)$ implicitly. Given $J^{*}$, the transformation function determines sorrow: $S^{*}=J^{*}-e^{*}$.

As for the remaining variables, equation (8) determines the equilibrium stock of capital of Spinoza's solution, denoted by the superscript B:

$$
k^{B}=\left(\frac{n+\theta}{\xi(1+a \varepsilon)}\right)^{1 /(\xi-1)}
$$

Given $k^{B}$, it follows that equation (9) determines equilibrium consumption $c^{B}$ and equation (10) the co-state variable, $\lambda^{B}$.

\subsection{Pessimism: William James's solution}

The third solution of interest is the William James solution, pessimism. In this solution joy is transformed into sorrow: $S=J+e$, we can rewrite this equation as: $J=S-e$ so as to eliminate joy from the Spinoza model. In order to find James's solution let us consider the corresponding Hamiltonian function:

$$
\mathrm{H}=c^{\alpha}+(S-e)^{\beta}+S^{\delta}+\lambda\left[(1-a e) k^{\xi}-n k-c\right]
$$

In the steady state: $\dot{k}=\dot{\lambda}=0$ the optimality conditions are: 


$$
\begin{gathered}
\beta(S-e)^{\beta-1}+\delta S^{\delta-1}=0 \\
(1-a e) \xi k^{\xi-1}=n+\theta \\
(1-a e) k^{\xi}=n k+c \\
\alpha c^{\alpha-1}=\lambda
\end{gathered}
$$

As in the Spinoza solution, in the William James solution emotions are independent from economics variables. Equation (12) determines implicitly the equilibrium value of sorrow, $S^{*}$, and the transformation function, $J=S-e$, determines the equilibrium value of joy, $J^{\star}$. In both solutions, Spinoza and William James, joy and sorrow, and therefore happiness, cannot be explained by economics; for instance, for an individual's happiness it does not matter if the individual is rich or poor, or if his consumption level is high or low. In Spinoza and James solutions only the utility parameters $\beta$ and $\delta$ and the transformation of emotions parameter, $e$, matter for the determination of emotions.

The equilibrium capital stock in the James solution, denoted by the superscript $W$, is determined by equation (13):

$$
k^{W}=\left(\frac{n+\theta}{\xi(1-a \varepsilon)}\right)^{1 /(\xi-1)}
$$

Given $k^{W}$, it follows that equation (14) determines equilibrium consumption $c^{W}$ and equation (15) the co-state variable, $\lambda W$.

\subsection{Comparing Spinoza, James and Ramsey solutions}

In order to compare the solutions of the Spinoza's model - Ramsey (neutral), Spinoza (optimism) and James (pessimism) solutions - we must assume $a=1$. Let us first contrast the capital stock of the Ramsey model, equation (1'), with the Spinoza solution, equation (10), and the William James solution, equation (16). One can see that optimists accumulate more capital than individuals that balance their emotions, corresponding to the Ramsey model, and that pessimism leads to a lower level of capital accumulation than the other two solutions: $k^{B}>k^{*}>k^{W}$. As a consequence, it follows that the equilibrium income and consumption are greater in the Spinoza solution than in the Ramsey and James solution $\left[f\left(k^{B}\right)>f\left(k^{*}\right)>f\left(k^{W}\right)\right.$ and $\left.c^{B}>c^{*}>c^{W}\right]$.

Therefore, in the Spinoza's model optimism leads to greater capital accumulation, income and consumption levels, while pessimism leads to the worse economic performance. The Ramsey model lies in between these two 


\section{$J$ Faria}

solutions, showing that the neoclassical growth model can be seen as a particular case of the Spinoza model in which emotions play little role in economics because they are assumed to balance.

\section{CONCLUDING REMARKS}

This paper considers the Ethics of Spinoza in a stylised neoclassical growth model. The main characteristics of the Spinoza model refer to an extra constraint describing the transformation of emotions, and extended utility and production functions, that incorporate emotions such as joy and sorrow, as arguments.

The model has multiple equilibria and we focus on three particular solutions related to joy and sorrow, or, more broadly, how an individual conceives life. The optimist transforms sorrow into joy and the pessimist transforms joy into sorrow. The optimist solution is the Spinoza solution because it is in line with the prescriptions of Spinoza's Ethics. The pessimist solution is called the William James solution that considered pessimism good. The solution in which there is a balance between joy and sorrow corresponds to the equilibrium in the traditional Ramsey model. As for Spinoza the rational understanding of emotions is the key to happiness. We may refer the results of Spinoza's model dealing with emotions to happiness.

The results of the model are very appealing. First, the way we conceive and understand our lives, being optimistic or pessimistic, affect our economic behaviour, making a difference in terms of economic growth, i.e., capital accumulation, and also affect other macroeconomic variables such as consumption and income. It is shown that optimism leads to greater capital accumulation, income and consumption levels, while pessimism leads to the worse economic performance. Second, we show that the Ramsey model lies between the Spinoza and James solutions and consequently it can be seen as a particular case of Spinoza's model, in which joy and sorrow balance. Finally, regarding the relationship between emotions and economics, in the Spinoza and William James solutions emotions [happiness] are determined independently from economic variables. Only in the Ramsey case are emotions [happiness] explained by income and consumption.

Accepted for publication: 19 July 2011

\section{ENDNOTES}

1. J.R. Faria, MPA Program, University of Texas at El Paso, 500 West University Avenue, KEH 410, El Paso, Texas, 79968-0703, USA. Phone: 915-747-8938; Fax: 915747-7948. Email: rfaria2@utep.edu. I would like to thank, without implication, Mauro Boianovsky, two anonymous referees and the editor Bruce Philp, for useful comments. 
2. Wagener (1994) points out that Spinoza develops in his Ethics the microfoundations of human action.

3. Apparently Montaigne (1595) had anticipated this issue in his Essay De la Tristesse (Livre I, Chapitre II).'

4. For Spinoza, a poor man who is miserly and who does not act rationally "will talk incessantly of the misuse of wealth and of the vices of the rich; whereby he merely torments himself, and shows the world that he is intolerant, not only of his own poverty, but also of other people's riches' (Ethics, V, Prop. X, Note).

5. In this regard we bypass the large literature on economics, ethics and cooperation (e.g. Carter and Irons, 1991, Thaler, 1991 and Frank et al., 1993).

6. See Faria (1998) for the disruptive effects of envy in academic work.

\section{REFERENCES}

Barbalet J (2008) 'Pragmatism and economics: William James' contribution', Cambridge Journal of Economics, 32, 797-810.

Carter J and Irons M (1991) 'Are Economists Different, and If So, Why?', Journal of Economic Perspectives, 5, 171-177.

Clark A E, Georgellis Y and Sanfey P (2001) 'Scarring: The psychological impact of past unemployment', Economica, 68, 221-41

Damasio A (2003) Looking for Spinoza, Orlando: Harcourt.

Faria J R (1998) 'The economics of witchcraft and the big eye effect', Kyklos, 51, 537546.

Frey B S and Stutzer A (2002) Happiness and Economics: How the Economy and Institutions Affect Well-Being, Princeton: Princeton U P.

Frey B S and Stutzer A (2005) 'Happiness research: State and prospects', Review of Social Economy, 62, 207-228.

Frank R H, Gilovich T and Regan D T (1993) 'Does studying economics inhibit cooperation', Journal of Economic Perspectives, 7, 159-171.

Hodgson G M (2003) 'The hidden persuaders: institutions and individuals in economic theory', Cambridge Journal of Economics, 25, 651-660.

James W (2004,[1902]) The Varieties of Religious Experience, New York: Barnes \& Noble Classics.

Lawlor M S (2006) 'William James' psychological pragmatism: Habit, belief and purposive human behavior', Cambridge Journal of Economics, 30, 321-345.

Montaigne M (1595) Les Essais, http://www.bribes.org/trismegiste/montable.htm.

Moore G E (2005,[1903]) Principia Ethica, New York: Barnes \& Noble Classics. 


\section{$J$ Faria}

Namazie C and Sanfey P (2001) 'Happiness and transition: The case of Kyrgyzstan', Review of Development Economics, 5, 392-405.

Oswald A (1997) 'Happiness and economic performance', Economic Journal, 107, 18151831.

Spinoza B (1989, [1677]) Ethics including the Improvement of the Understanding, tr. by R. H. M. Elwes, Amherst: Prometheus Books.

Thaler R (1991) Quasi-Rational Economics, New York: Russell Sage Foundation.

Twomey P (1998) 'Reviving Veblenian economic psychology', Cambridge Journal of Economics, 22, 433-448.

Wagener H J (1994) 'Cupiditate et potential: The political economy of Spinoza', European Journal of the History of Economic Thought, 1, 475-493. 